\title{
Phytochelatins play a key role in arsenic accumulation and tolerance in the aquatic macrophyte Wolffia globosa
}

\author{
Xin Zhang ${ }^{\mathrm{a}}$, M. Kalle Uroic ${ }^{\mathrm{b}}$, Wan-Ying Xie ${ }^{\mathrm{c}}$, Yong-Guan Zhu ${ }^{\mathrm{a}, \mathrm{c}}$, Bao-Dong Chen ${ }^{\mathrm{a}}$, \\ Steve P. McGrath ${ }^{\mathrm{d}}$, Jörg Feldmann ${ }^{\mathrm{b}}$, Fang-Jie Zhao ${ }^{\mathrm{d}, \mathrm{e}, *}$ \\ a State Key Laboratory of Urban and Regional Ecology, Research Center for Eco-Environmental Sciences, Chinese Academy of Sciences, Beijing 100085, China \\ ${ }^{\mathrm{b}}$ College of Physical Science, Trace Element Speciation Laboratory (TESLA) Chemistry, University of Aberdeen, Meston Building, Aberdeen AB24 3UE, United Kingdom \\ ${ }^{\mathrm{c}}$ Institute of Urban Environment, Chinese Academy of Sciences, Xiamen 361021, China \\ ${ }^{\mathrm{d}}$ Rothamsted Research, Harpenden, Hertfordshire AL5 2JQ United Kingdom \\ ${ }^{\mathrm{e}}$ College of Resources and Environmental Sciences, Nanjing Agricultural University, Nanjing 210095, China
}

\section{A R T I C L E I N F O}

\section{Article history:}

Received 9 December 2011

Received in revised form

7 February 2012

Accepted 9 February 2012

\section{Keywords:}

Arsenic

Arsenic tolerance

Arsenic speciation

Phytochelatins

Wolffia globosa

\begin{abstract}
A B S T R A C $T$
The rootless duckweed Wolffia globosa can accumulate and tolerate relatively large amounts of arsenic (As); however, the underlying mechanisms were unknown. W. globosa was exposed to different concentrations of arsenate with or without L-buthionine sulphoximine (BSO), a specific inhibitor of $\gamma$ glutamylcysteine synthetase. Free thiol compounds and As(III)-thiol complexes were identified and quantified using HPLC - high resolution ICP-MS - accurate mass ESI-MS. Without BSO, 74\% of the As accumulated in the duckweed was complexed with phytochelatins (PCs), with $\mathrm{As}(\mathrm{III})-\mathrm{PC}_{4}$ and $\mathrm{As}(\mathrm{III})$ $-\mathrm{PC}_{3}$ being the main species. BSO was taken up by the duckweed and partly deaminated. The BSO treatment completely suppressed the synthesis of PCs and the formation of As(III)-PC complexes, and also inhibited the reduction of arsenate to arsenite. BSO markedly decreased both As accumulation and As tolerance in W. globosa. The results demonstrate an important role of PCs in detoxifying As and enabling As accumulation in W. globosa.
\end{abstract}

(C) 2012 Elsevier Ltd. All rights reserved.

\section{Introduction}

Arsenic (As) is a class-one carcinogen (National Research Council, 2001). Arsenic contamination in the environment is widespread due to both geogenic and anthropogenic activities. Globally 150 million people are exposed to unsafe levels of As in the drinking water (Brammer and Ravenscroft, 2009). In addition to drinking water, food, especially rice, is also an important source of inorganic As in the diet of some populations (Meharg et al., 2009; Zhu et al., 2008). The common practice of irrigating paddy rice with As-contaminated groundwater in south and southeast Asia may lead to further elevation of As in the food chain (Dittmar et al., 2010; Meharg and Rahman, 2003). Mitigation of As contamination in the environment and in the food chain requires a better understanding of the As biogeochemcal cycle, including the processes of As accumulation and detoxification in the biota (Zhao et al., 2010b).

In aquatic environments or paddy fields, aquatic plants with a high capacity to accumulate As may be used to clean up the

\footnotetext{
* Corresponding author.

E-mail addresses: Fangjie.Zhao@njau.edu.cn, Fangjie.Zhao@rothamsted.ac.uk (F.-J. Zhao).
}

contaminant in the water (Rahman and Hasegawa, 2011). Arsenic accumulation has been investigated in a number of aquatic macrophytes (Rahman and Hasegawa, 2011; Robinson et al., 2006; Srivastava et al., 2007; Zhang et al., 2008). W. globosa L., a rootless duckweed widely distributed in ponds and paddy fields, was found to be a strong accumulator of As with a relatively high tolerance to the metalloid (Zhang et al., 2009); both of these characteristics are prerequisite for efficient phytoremediation. However, the mechanism of As tolerance in this macrophyte was unknown.

The mechanisms of As tolerance have been extensively studied in terrestrial plants (reviewed by Zhao et al., 2009). Plants are able to take up both arsenate $(\mathrm{As}(\mathrm{V}))$ and arsenite $(\mathrm{As}(\mathrm{III}))$ via phosphate transporters and some aquaporin channels, respectively. Both forms of As are toxic to cellular metabolism; arsenate interferes with phosphate metabolism such as phosphorylation, whilst arsenite can inactivate enzymes by binding to the sulphydryl groups of the proteins (Hughes, 2002; Ullrich-Eberius et al., 1989). Detoxification of As may involve reduction of arsenate to arsenite, efflux of arsenite to the external medium, complexation of arsenite by thiolrich peptides and compartmentation of As(III)-thiol complexes in the vacuoles (Zhao et al., 2009). There is strong evidence that phytochelatins (PCs) play a crucial role in arsenite detoxification in 
terrestrial plants. PC-deficient mutants of Arabidopsis thaliana were found to be much more sensitive to As than the wild-type plants (Ha et al., 1999; Liu et al., 2010). Over-expression of PC synthase enhanced As tolerance in the transgenic plants (Gasic and Korban, 2007; Guo et al., 2008; Li et al., 2004). In contrast, use of Lbuthionine sulphoximine (BSO) to inhibit the synthesis of glutathione (GSH) and PCs resulted in greatly increased sensitivity to As in a number of plant species (Schat et al., 2002; Schmöger et al., 2000). Recent studies have also identified a number of As(III)thiol complexes in plant extracts (Bluemlein et al., 2008; Liu et al., 2010; Raab et al., 2007). Furthermore, two ABC transporters able to mediate the transport of As(III)-PCs into the vacuoles have recently been identified in Arabidopsis (Song et al., 2010). Unlike As non-hyperaccumulating plants, As hyperaccumulating ferns (e.g., Pteris vittata) appear to employ a PC-independent mechanism of As detoxification, with only a very small proportion of the As taken up being complexed with PCs (Raab et al., 2004; Webb et al., 2003; Zhang et al., 2004; Zhao et al., 2003). In these plants, arsenate is reduced to arsenite, which is sequestered in the vacuoles mostly in the non-complexed form (Lombi et al., 2002; Pickering et al., 2006), probably via the tonoplast arsenite transporter PvACR3 (Indriolo et al., 2010). The mechanisms of As tolerance in aquatic macrophytes are not well understood. Studies with the Esthwaite waterweed Hydrilla verticillata showed that As exposure was accompanied by increased PC synthesis and that increasing the sulphur supply enhanced As tolerance as well as As accumulation (Srivastava and D'Souza, 2009; Srivastava et al., 2007).

The objectives of this study were to identify and quantify As(III)-thiol complexes and to investigate the role of thiol-rich peptides in As tolerance and accumulation in W. globosa.

\section{Materials and methods}

\subsection{Plant culture}

W. globosa L. was collected from Wuhan, Hubei province, China, and maintained in a half-strength Hoagland nutrient solution. Progeny from this original stock was used in the present study. Plants were grown in the half-strength Hoagland solution for 3 weeks before being used in experiments. The composition of the nutrient solution was as follows: $2 \mathrm{mM} \mathrm{CaNO}_{3}, 3 \mathrm{mM} \mathrm{KNO}_{3}, 1 \mathrm{mM} \mathrm{MgSO}_{4}, 0.5 \mathrm{mM} \mathrm{NH}_{4} \mathrm{H}_{2} \mathrm{PO}_{4}$ $100 \mu \mathrm{M}$ Fe-EDTA, $46 \mu \mathrm{M} \mathrm{H}_{3} \mathrm{BO}_{3}, 9 \mu \mathrm{M} \mathrm{MnCl}_{2}, 0.75 \mu \mathrm{M} \mathrm{ZnSO}_{4}, 0.35 \mu \mathrm{M} \mathrm{CuSO}_{4}$ and $0.55 \mu \mathrm{M} \mathrm{Na}_{2} \mathrm{MoO}_{4}$ (pH adjusted to 6.0 with $\mathrm{KOH}$ or $\mathrm{HCl}$ solutions). Nutrient solution was renewed twice every week. The hydroponic culture and all experiments were conducted inside a controlled-environment growth chamber with the following conditions: $14 \mathrm{~h}$ light period $\mathrm{d}^{-1}$ with a light intensity of $c .280 \mu \mathrm{mol} \mathrm{m} \mathrm{m}^{-2} \mathrm{~s}^{-1}, 25$ : $20{ }^{\circ} \mathrm{C}$ day : night temperatures, and $70 \%$ relative humidity.

\subsection{Arsenate accumulation, speciation and tolerance in W. globosa}

After preculture for 3 weeks, W. globosa plants were transferred to 28 pots ( $80 \mathrm{ml}, 3 \mathrm{~g}$ plant material per pot) and treated with $500 \mu \mathrm{M}$ L-buthionine sulphoximine (BSO) for $5 \mathrm{~d}$; another group of 28 pots not treated with BSO served as the control. Thereafter, plants in both groups were exposed to $0,1,5,10,30,50,100 \mu \mathrm{M}$ arsenate $\left(\mathrm{Na}_{3} \mathrm{AsO}_{4}\right)$ for $5 \mathrm{~d}$, with or without $500 \mu \mathrm{M}$ BSO. Each As and BSO treatment was replicated in four pots. After 5 day exposure, plants were harvested, washed with deionized water, and then immersed in an ice-cold desorption solution containing $1 \mathrm{mM} \mathrm{K}_{2} \mathrm{HPO}_{4}, 0.5 \mathrm{mM} \mathrm{Ca}\left(\mathrm{NO}_{3}\right)_{2}$, and $5 \mathrm{mM} \mathrm{MES} \mathrm{(pH} \mathrm{5.5)} \mathrm{for} 15 \mathrm{~min}$ to remove apoplastic As. Plants were blotted dry, weighed, frozen in liquid nitrogen and freeze-dried. The concentrations of total As and As speciation were determined as described below.

\subsection{Arsenate uptake and arsenite efflux}

Four replicates of $3 \mathrm{~g} \mathrm{~W}$. globosa were treated with $200 \mathrm{ml} 500 \mu \mathrm{M}$ BSO for $3 \mathrm{~d}$; another group was not treated with BSO. Three days later, plants were exposed to $5 \mu \mathrm{M}$ arsenate, with or without $500 \mu \mathrm{M}$ BSO. Aliquots of $0.5 \mathrm{ml}$ nutrient solution were collected at $1,5,10$ and $24 \mathrm{~h}$, diluted with $4.5 \mathrm{ml}$ phosphate-buffered solution (PBS, $2 \mathrm{mM} \mathrm{NaH}_{2} \mathrm{PO}_{4}$ and $0.2 \mathrm{mM} \mathrm{Na}_{2}$-EDTA, pH 6.0), and filtered through $0.45 \mu \mathrm{m}$ before analysis of As speciation. Arsenate uptake and arsenite efflux were calculated from the decrease of arsenate and the appearance of arsenite in the nutrient solution, respectively. After $24 \mathrm{~h}$, plants were harvested for total As and As speciation analysis as described below. To evaluate the potential role of microorganisms versus
W. globosa in mediating arsenate reduction in the uptake solution, arsenate $(5 \mu \mathrm{M})$ was added to three solutions: fresh nutrient solution without W. globosa, fresh nutrient solution with $3 \mathrm{~g} \mathrm{W.} \mathrm{globosa}$, and old nutrient solution that had been used to grow $W$. globosa for 3 days and with the duckweed subsequently removed. Each treatment was replicated in 4 pots. Arsenic speciation in the nutrient solutions was monitored at $1,5,10$ and $24 \mathrm{~h}$.

\subsection{Arsenite complexation with thiol compounds}

W. globosa ( $3 \mathrm{~g}$ ) was incubated in $50 \mathrm{ml}$ nutrient solution with the phosphate concentration being lowered to $0.05 \mathrm{mM}$. Four replicates were treated with $500 \mu \mathrm{M}$ BSO for $3 \mathrm{~d}$ and another group was not treated with BSO. Three days later, plants were exposed to $10 \mu \mathrm{M}$ arsenate with or without $500 \mu \mathrm{M}$ BSO for 4 days. Plants were harvested and As(III)-thiol complexes and free thiol compounds determined as described below.

\subsection{Analysis of total As in plant tissues}

Ground plant samples were digested in $5 \mathrm{ml}$ high-purity $\mathrm{HNO}_{3} / \mathrm{HClO}_{4}(87 / 13$, v/ v). Total As concentrations in the digests were determined by ICP-MS (Agilent $7500 \mathrm{ce}$ ) operating in the helium gas mode to remove possible interference of ${ }^{40} \mathrm{Ar}{ }^{35} \mathrm{Cl}$ on $\mathrm{m} / \mathrm{z} 75$.

\subsection{Analysis of As speciation in plant tissues}

Samples were ground in liquid nitrogen to fine powder with a mortar and pestle. Samples $(0.1 \mathrm{~g})$ were extracted with $10 \mathrm{ml}$ PBS solution for $1 \mathrm{~h}$ under sonication. The extract was filtered through Whatman NO. 42 filter paper and then a $0.2 \mu \mathrm{m}$ filter. The efficiency of As extraction by PBS was approximately $60 \%$. Arsenic speciation was determined by anion-exchange HPLC-ICP-MS (Agilent LC1100 series and Agilent ICP-MS 7500ce; Agilent Technologies). Chromatographic columns consisted of a Hamilton precolumn $(11.2 \mathrm{~mm}, 12-20 \mathrm{~mm})$ and a Hamilton PRP-X100 $10 \mu \mathrm{m}$ anion-exchange column $(150 \times 4.1 \mathrm{~mm})$. As species [As(III), As(V), DMA, and MMA] were separated with a mobile phase of $4.4 \mathrm{mM} \mathrm{NH}_{4} \mathrm{H}_{2} \mathrm{PO}_{4}$ and $4.4 \mathrm{mM} \mathrm{NH}_{4} \mathrm{NO}_{3}$, $0.2 \mathrm{mM}$ EDTA and $2.5 \%(\mathrm{v} / \mathrm{v})$ methanol ( $\mathrm{pH} 6.2)$, run isocratically at $0.65 \mathrm{~mL} \mathrm{~min}^{-1}$. Germanium $(\mathrm{Ge})$ as an internal standard was mixed continuously with the postcolumn solution through a peristaltic pump. Signals at $\mathrm{m} / \mathrm{z} 75$ (As) and 72 (Ge) were collected with a dwell time of 300 and $100 \mathrm{~ms}$, respectively. Possible polyatomic interference of ${ }^{40} \mathrm{Ar}{ }^{35} \mathrm{Cl}$ on $\mathrm{m} / \mathrm{z} 75$ was removed by the Agilent Octopole Reaction System operating in the helium gas mode. The As signal was normalized using the Ge signal to correct any signal drift during the analysis. As species in the samples were identified by comparisons with the retention times of standard compounds and quantified by external calibration curves with peak areas. Analysis of As species was carried out immediately following sample collection or extraction.

\subsection{Analysis of thiol compounds and As(III)-thiol complexes}

For the analysis of As(III)-thiol complexes and free thiols, duckweed samples were ground in liquid nitrogen to fine powder with a mortar and pestle. Samples $(1 \mathrm{~g})$ were then transferred to $15-\mathrm{ml}$ Grenier tubes, to which $5 \mathrm{ml}$ ice-cold $1 \%$ formic acid was added. Samples were extracted at $4{ }^{\circ} \mathrm{C}$ for $1 \mathrm{~h}$, with intermittent shaking by hand. Samples were subsequently centrifuged at $890 \mathrm{~g}$ for $3 \mathrm{~min}$ after extraction. Approximately $1 \mathrm{ml}$ of supernatant was then transferred to an Eppendorf vial, where the supernatant was further centrifuged at $7550 \mathrm{~g}$ for $5 \mathrm{~min}$ and used for speciation analysis. Analysis of As(III)-thiol complexes and free thiol compounds was carried out using HPLC coupled with high resolution ICP-MS (Element 2; Thermo Fisher Scientific) and high resolution ESI-MS (LTQ Orbitrap Discovery; Thermo Fisher Scientific), as described previously (Bluemlein et al., 2009; Liu et al., 2010). Separation was performed on a $\mathrm{C}_{18}$ reverse-phase column (Eclipse XDB-C18, $5 \mu \mathrm{m}$ ), using a water-methanol gradient. Starting from $100 \%$ water, methanol was added to the eluent at the rate of $1 \%$ per min over the first $20 \mathrm{~min}$. The eluent was held at $80 \%$ water $/ 20 \%$ methanol for a further $10 \mathrm{~min}$, followed by switching back to $100 \%$ water. Total chromatographic run time was $30 \mathrm{~min}$. For the ICP-MS analysis, As and S were measured on $\mathrm{m} / \mathrm{z} 75$ and 32, respectively. Germanium was added post-column as internal standard for the ICP-MS, and its signal was measured on $m / z 72$. For As and S quantification, a blank run was done for response factor (Rf) determination with a post-column addition of As, $\mathrm{S}$ and Ge. To account for the change in the sensitivity due to the methanol gradient, each chromatographic run was divided by the response factor run. These normalized chromatograms were used for peak integration with PeakFit and subsequent quantification. According to a previous study with sunflower plants (Raab et al., 2005), the method used extracted 70-90\% of the total As and the column recovery was appropriately $90 \%$. The As speciation determined by the method used was found to be in good agreement with that determined by non-destructive X-ray absorption spectrometry (Bluemlein et al., 2008).

\subsection{Data analysis}

All data were subjected to analysis of variance (ANOVA) using windows-based SPSS 13.0 


\section{Results}

\subsection{The effects of BSO on arsenic accumulation, speciation and tolerance}

In the 0 and $1 \mu \mathrm{M}$ arsenate treatments, the biomass of $W$. globosa increased by $5-7 \%$ during the exposure period, whereas in the high arsenate treatments ( $\geq 5 \mu \mathrm{M})$, the biomass decreased to below the initial amount ( $3 \mathrm{~g}$ ) because some of the duckweed died and sank to the bottom of the vessel (Fig. 1). Therefore, the biomass data reflect the growth in the zero and low As treatments and the survival in the high As treatments. In the 0 and $1 \mu \mathrm{M}$ arsenate treatments, the presence of BSO did not significantly affect the biomass of W. globosa (Fig. 1). However, with increasing arsenate concentration, biomass decreased more rapidly in the presence of BSO than in the -BSO control, except in the highest arsenate treatment $(100 \mu \mathrm{M})$ in which $W$. globosa suffered from severe As toxicity both with and without BSO. From the fitted dose-response curve (Fig. 1), the concentration of arsenate in the nutrient solution leading to a $20 \%$ inhibition $\left(\mathrm{EC}_{20}\right.$ ) was estimated to be 52.3 and $11.5 \mu \mathrm{M}$, respectively, in the absence or presence of BSO, indicating a 4.5 fold increase in the arsenate sensitivity with the addition of BSO.

Tissue As concentration increased significantly $(P<0.001)$ with increasing concentration of arsenate in the -BSO treatment, reaching a plateau of $755 \mathrm{mg} \mathrm{As} \mathrm{kg}^{-1} \mathrm{DW}$ in the $50 \mu \mathrm{M}$ arsenate treatment (Fig. 2). Increasing arsenate to $100 \mu \mathrm{M}$ did not lead to further increase in As accumulation by the duckweed, possibly due to severe toxicity. The presence of BSO decreased the tissue As concentration dramatically $(P<0.001)$, by up to 7 fold in the $50 \mu \mathrm{M}$ arsenate treatment.

The biomass of $W$. globosa was plotted against the total As concentration in the duckweed tissue in order to evaluate the effect of BSO on the tolerance to the internal As (Fig. 3). This shows a much more rapid decline in biomass with increasing tissue As concentration in the presence of BSO than in the - BSO treatment. A $20 \%$ inhibition of biomass was obtained at tissue As concentrations of 785 and $54 \mathrm{mg} \mathrm{kg}^{-1}$ DW in the - BSO and + BSO treatments, respectively, suggesting a 14.5 fold difference in tolerance.

BSO not only affected As accumulation in W. globosa, but also As speciation in the duckweed. In the absence of BSO, 93-98\% (mean 96\%) of the As in W. globosa was present in the form of As(III) (Fig. 4), indicating a strong arsenate reduction capacity. In the

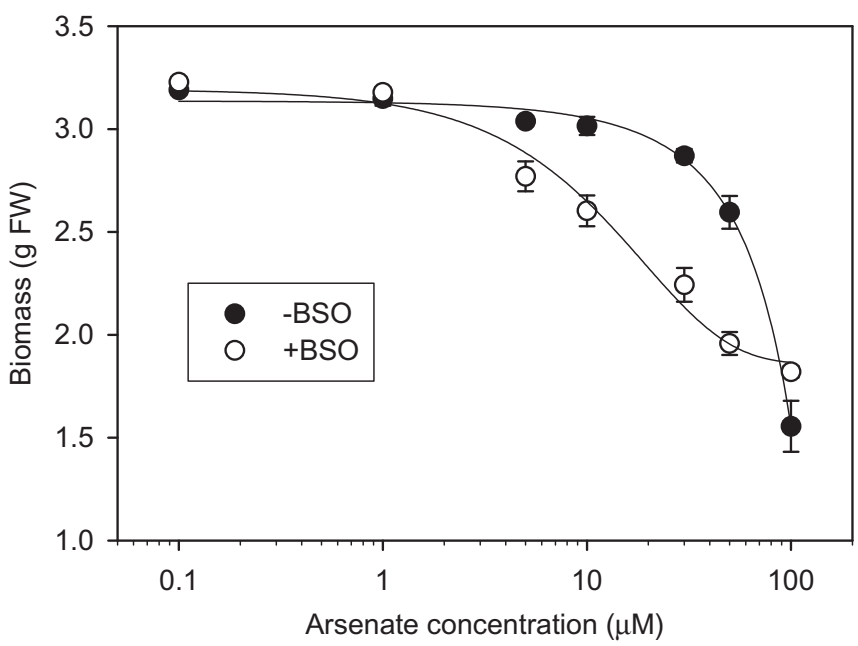

Fig. 1. Effects of L-buthionine-sulfoximine (BSO) and arsenate exposure on the biomass of Wolffia globosa. Data are mean $\pm \operatorname{SE}(n=4)$. Lines are the fitted Sigmoidal curves. To allow log transformation, a small value $(0.1)$ was added to the zero As concentration in the control treatment.

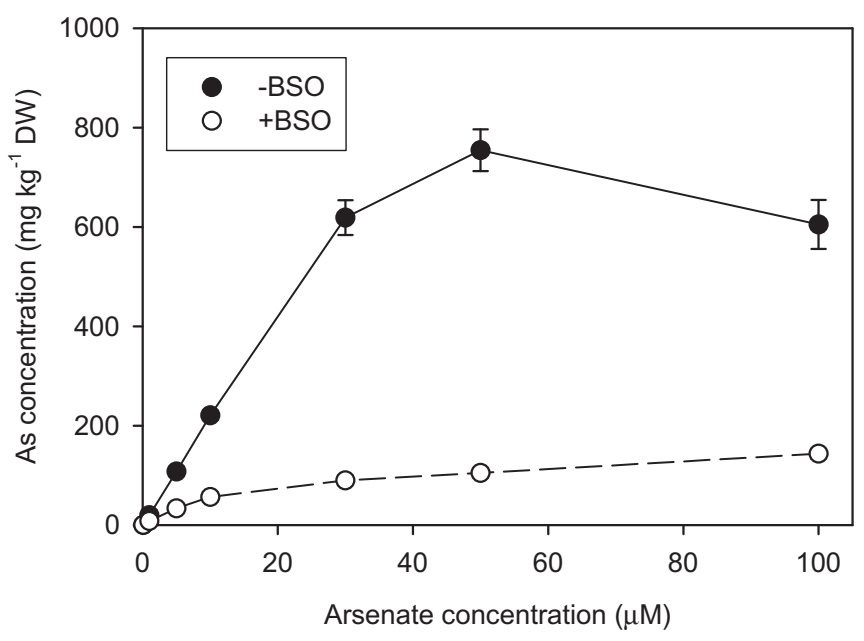

Fig. 2. Effects of L-buthionine-sulfoximine (BSO) and arsenate exposure on arsenic concentration in Wolffia globosa. Data are mean \pm SE $(n=4)$.

presence of BSO, the proportion of As(III) in the duckweed tissue decreased to $57-84 \%$ (mean $71 \%$ ). No methylated As species was detected in the $W$. globosa samples.

\subsection{BSO effects on arsenate uptake and arsenite efflux}

To investigate whether BSO affects arsenate uptake and/or arsenite efflux directly, a time-course experiment was conducted to monitor the changes in As speciation in the uptake solution which initially contained only arsenate. During the $24 \mathrm{~h}$ time course, the concentration of arsenate in the nutrient solution decreased while that of arsenite increased (Fig. 5). There was no significant difference in the pattern of As species change between the - BSO and +BSO treatments during the initial $10 \mathrm{~h}$; at $10 \mathrm{~h}$ approximately $25 \%$ of the As in the nutrient solution was in the form of $\mathrm{As}(\mathrm{III})$. Arsenate uptake and arsenite efflux continued up to $24 \mathrm{~h}$ in the -BSO treatment, but appeared to have stopped after $10 \mathrm{~h}$ in the + BSO treatment. At $24 \mathrm{~h}$, As(III) accounted for $54 \%$ of the total As in the nutrient solution in the -BSO treatment, compared with only $20 \%$ in the + BSO treatment.

It is possible that the reduction of arsenate to arsenite in the uptake solution might be mediated by the microorganisms. To test

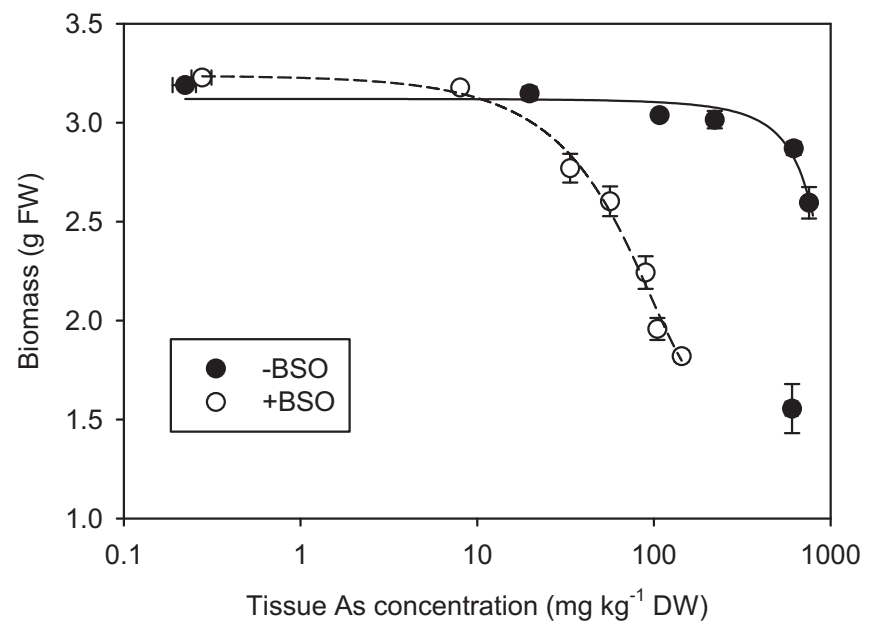

Fig. 3. Relationship between the biomass of Wolffia globosa and tissue arsenic concentration after 5 days exposure to different concentrations of arsenate with or without BSO treatment. Lines are the fitted sigmoidal curves. 

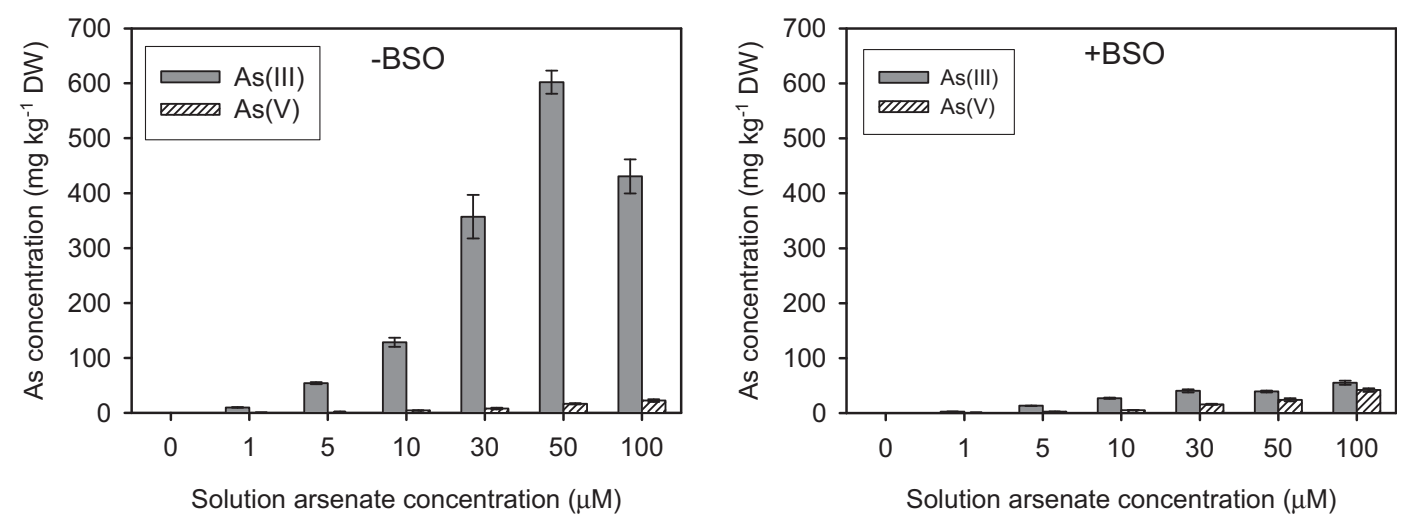

Fig. 4. Arsenic (As) speciation in Wolffia globosa after exposure to different arsenate concentrations for 5 days treated with BSO or without BSO

this possibility, arsenate reduction was monitored in fresh nutrient solution with or without $W$. globosa, as well as in an old nutrient solution that had been used to grow W. globosa, which would have enhanced microbial activities. Over the $24 \mathrm{~h}$ period, arsenate was not reduced to arsenite in the fresh nutrient solution without $W$. globosa (Supplementary Fig. S1). In the presence of $W$. globosa, a substantial amount of arsenate was reduced to arsenite in the solution. In contrast, only a very small amount of arsenate was reduced to arsenite in the old nutrient solution but without W. globosa; the amount of arsenite produced during 1-24 h was $\leq 7 \%$ of that in the presence of $W$. globosa (Supplementary Fig. S1). In both the fresh solution with $W$. globosa and the old solution without $W$. globosa, the decrease in arsenate concentration was more than the increase in arsenite concentration, likely due to the uptake of As by the duckweed in the former or some adsorption of arsenate by the debris in the latter. These results indicate that the reduction of arsenate to arsenite was mediated predominantly by $W$. globosa. This conclusion is also consistent with previous studies using terrestrial plants (Xu et al., 2007; Zhao et al., 2010a).

\subsection{As(III) complexation with PCs and GSH}

Reverse-phase HPLC coupled to high resolution ICP-MS and accurate mass high resolution electrospray ionization (ESI-MS)

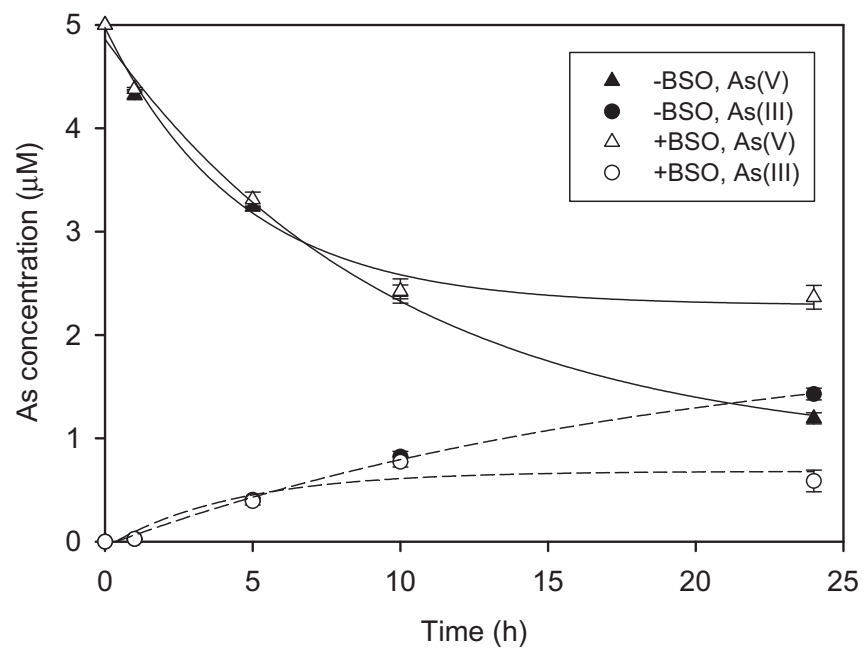

Fig. 5. Changes of As species in the nutrient solution during $24 \mathrm{~h}$. Wolffia globosa was initially exposed to $5 \mu \mathrm{M}$ arsenate treated with or without $500 \mu \mathrm{M}$ BSO. Data are means \pm SE $(n=4)$. were used to quantify As(III)-thiol complexes and free thiol compounds in duckweed exposed to arsenate $\mathrm{As}(\mathrm{V})$ in the presence or absence of BSO. This analytical method allows the identification and quantification of different $\mathrm{As}(\mathrm{III})$-thiol complexes and free thiol compounds (Bluemlein et al., 2009; Liu et al., 2010). Fig. $6 \mathrm{~A}$ and $\mathrm{B}$ show the $\mathrm{S}$ and As Signals in the duckweed extracts from the -BSO treatment, measured by the high resolution ICPMS. The identity of the As and S peaks were then deduced from the molecular data obtained by the high resolution ESI-MS (Fig. 6C-K). The first As and S peaks eluted in the void volume at around $120 \mathrm{~s}$ were uncomplexed inorganic As (arsenite and arsenate) and inorganic $S$ (sulphate). In the -BSO treatment (Fig. 6), a number of As peaks, eluted after $500 \mathrm{~s}$, represented different As(III)-thiol complexes. Using ESI-MS (Fig. 6C-E), three As peaks were identified as $\mathrm{As}(\mathrm{III})-\mathrm{GS}-\mathrm{PC}_{2}, \mathrm{As}(\mathrm{III})-\mathrm{PC}_{3}$ and $\mathrm{As}(\mathrm{III})-\mathrm{PC}_{4}$, respectively. The $\mathrm{As}(\mathrm{III})-\mathrm{PC}_{4}$ complex appears as two peaks representing four structural isomers of the $\mathrm{As}(\mathrm{III})-\mathrm{PC}_{4}$ complex that are not fully separated at the baseline by the HPLC method used. The molecular proof for the two small peaks (retention times RT $=1178$ and $1224 \mathrm{~s}$, respectively), between $\mathrm{As}(\mathrm{III})-\mathrm{PC}_{3}$ and $\mathrm{As}(\mathrm{III})-\mathrm{PC}_{4}$, could not be obtained in the ESI-MS. However, these two peaks occurred at the same retention times as the two isomers of $\mathrm{As}(\mathrm{III})-\left(\mathrm{PC}_{2}\right)_{2}$ which were identified in the Arabidopsis extracts using the same method (Liu et al., 2010). They are therefore tentatively designated as $\mathrm{As}(\mathrm{III})-\left(\mathrm{PC}_{2}\right)_{2}$. One minor peak at the retention times of $504 \mathrm{~s}$ could not be identified.

In contrast to the -BSO treatment, no As(III)-thiol complex was detected in the extracts from the $+\mathrm{BSO}$ treatment (Fig. 7E). Table 1 shows the concentrations of unbound As and $\mathrm{As}(\mathrm{III})$-thiol complexes in W. globosa treated with and without BSO, quantified from the ICP-MS As data. Without BSO, 74\% of the As was complexed with thiols, with the most abundant complex being As(III)$\mathrm{PC}_{4}$ (accounting for 32\%), followed by As(III)-PC 3 (28\%), $\mathrm{As}(\mathrm{III})-\left(\mathrm{PC}_{2}\right)_{2}(9.6 \%)$ and $\mathrm{As}(\mathrm{III})-\mathrm{GS}-\mathrm{PC}_{2}(2.7 \%)$. In the presence of $\mathrm{BSO}$, all of the As in the extract was uncomplexed. The sum of As determined by the method (29.7 and $9.7 \mathrm{nmol} \mathrm{g}^{-1} \mathrm{FW}$ for -BSO and $+\mathrm{BSO}$, respectively, Table 1 ) agreed well with that by the PBS extraction followed by As determination using anion-exchange HPLC-ICP-MS (26.0 and $14.1 \mathrm{nmol} \mathrm{g}^{-1} \mathrm{FW}$ for $-\mathrm{BSO}$ and +BSO, respectively).

By combining the ICP-MS $m / z 32 \mathrm{~S}$ signal (Fig. 6A) and the ESIMS signal (Fig. 6F-K), a number of free thiol compounds could be identified and quantified in the -BSO extracts (Table 2). These include reduced $\mathrm{GSH}$, reduced and oxidized $\mathrm{PC}_{2}$ and $\mathrm{PC}_{3}$, and oxidized $\mathrm{PC}_{4}$, with reduced $\mathrm{GSH}$ being the most abundant thiol compound. In the presence of BSO, W. globosa produced no 

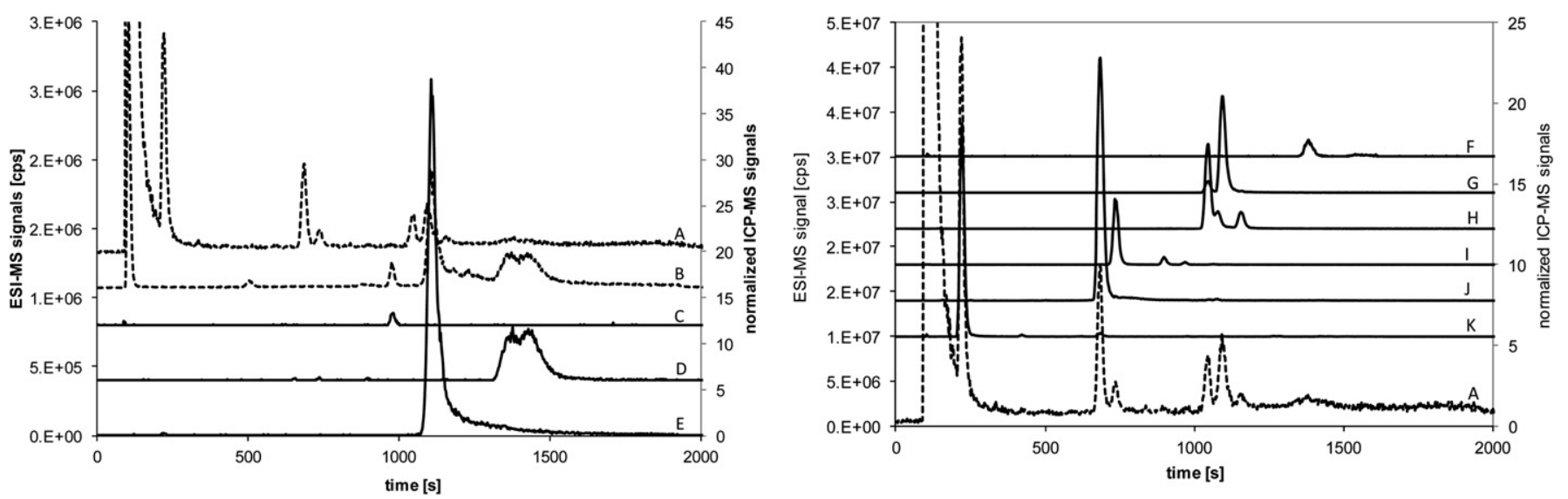

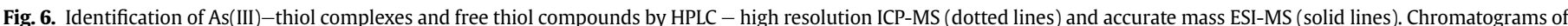

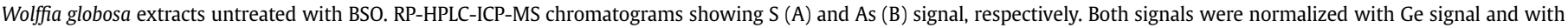

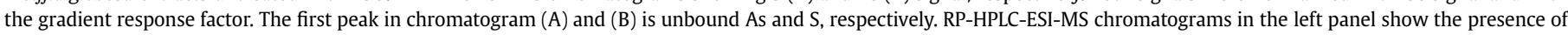

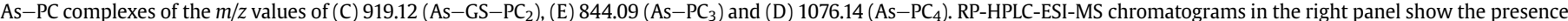

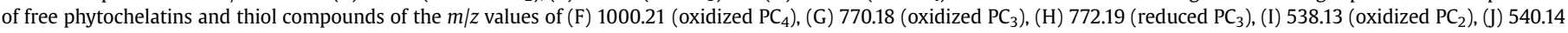
(reduced $\mathrm{PC}_{2}$ ) and (K) $308.09(\mathrm{GSH})$. Chromatograms are shifted for clarity; the signals of $\mathrm{As}(\mathrm{B})$ and oxidized $\mathrm{PC}_{4}(\mathrm{~F})$ are magnified by a factor of 7 and 10 , respectively.

detectable amounts of either free thiol compounds or As(III)-thiol complexes (Fig. 7); instead, a substantial amount of BSO $(\mathrm{m} / \mathrm{z} 223.11$ for the protonated BSO) was detected in the extract (Fig. 7A, D). Two other $\mathrm{S}$ peaks had a $\mathrm{m} / \mathrm{z}$ of 224.09 and 309.11, respectively (Fig. 7B, $\mathrm{C})$; the first is likely to be a deaminated alcohol of BSO, with either the $=\mathrm{NH}$ group in BSO being replaced with $=\mathrm{O}$ or the $-\mathrm{NH}_{2}$ group being replaced with $-\mathrm{OH}$ (Supplementary Fig. S2). Either of the replacements would increase $\mathrm{m} / \mathrm{z}$ by 1 . Approximately $12 \%$ of the BSO in the extract was deaminated (Table 2). The third peak is possibly also a BSO metabolite, although the identity remains unknown.

\section{Discussion}

The use of HPLC - high resolution ICP-MS - accurate mass ESIMS has allowed the identification and quantification of intact As(III)-thiol complexes in an aquatic macrophyte that is common in fresh water and paddy fields. The present study has shown that PCs play a crucial role in As tolerance in W. globosa, which has

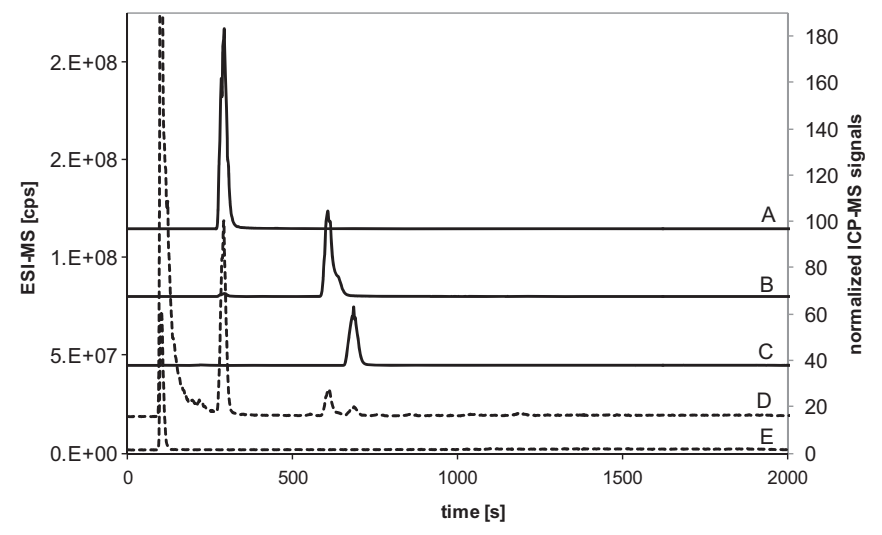

Fig. 7. Analysis of Wolffia globosa extracts treated with BSO by HPLC - high resolution ICP-MS (dotted lines) and accurate mass ESI-MS (solid lines). RP-HPLC-ICP-MS chromatograms show As (E) and S (D) signal, respectively. Both signals were normalized with Ge signal and with the gradient response factor. The first peak in chromatograms (E) and (D) is unbound As and S, respectively. RP-HPLC-ESI-MS chromatogram show the $m / z$ values of (A) 223.11 (BSO), (B) 224.09 (deaminated alcohol of BSO), and (C) 309.11 (unknown). Chromatograms are shifted for clarity; the signal of As (E) is magnified by a factor of 10 . a relatively high capacity to accumulate As (Fig. 2) (Zhang et al., 2009). The duckweed exposed to arsenate synthesized a range of $\mathrm{PCs}$, including $\mathrm{PC}_{2}, \mathrm{PC}_{3}$ and $\mathrm{PC}_{4}$, which served to complex the majority (74\%) of the As accumulated in the plant (Fig. 6, Tables 1 and 2). $\mathrm{As}(\mathrm{III})-\mathrm{PC}_{4}$ and $\mathrm{As}(\mathrm{III})-\mathrm{PC}_{3}$ were found to be the most important complexes, with $\mathrm{As}(\mathrm{III})-\left(\mathrm{PC}_{2}\right)_{2}$ and $\mathrm{As}(\mathrm{III})-\mathrm{GS}-\mathrm{PC}_{2}$ accounting for smaller proportions of the As. Despite the abundant presence of GSH in the duckweed tissue, As(III)- $\mathrm{GS}_{3}$ was not detected, probably because this complex is thermodynamically less stable than $\mathrm{As}(\mathrm{III})-\mathrm{PC}_{\mathrm{x}}$ complexes. Similarly, Liu et al. (2010) showed that about $70 \%$ of As in the roots of $A$. thaliana was complexed as $\mathrm{As}(\mathrm{III})-\mathrm{PC}_{4}, \mathrm{As}(\mathrm{III})-\mathrm{PC}_{3}$ and $\mathrm{As}(\mathrm{III})-\left(\mathrm{PC}_{2}\right)_{2}$, whereas $\mathrm{As}(\mathrm{III})-\mathrm{GS}_{3}$ was detected only in the PC-deficient mutant. The extent of As(III)-thiol complexation in W. globosa was much greater than that in the aquatic plant $H$. verticillata (maximum $39 \%$ ), although the estimate for $H$. verticillata was made indirectly based on the measurements of As and PC concentrations with the assumption of an 1 As : 3 -SH stoichiometry (Srivastava et al., 2007).

The presence of BSO completely suppressed the synthesis of GSH and PCs in W. globosa, resulting in no complexation of As in the duckweed (Fig. 7, Tables 1 and 2). BSO is a specific and potent inhibitor of $\gamma$-glutamylcysteine synthetase through its binding to the active centre of the enzyme (Griffith and Meister, 1979), $\gamma$ glutamylcysteine being the precursor of GSH and PCs. Interestingly, BSO and two possible metabolites of BSO were detected in the duckweed tissue exposed to BSO. One of the metabolites was likely to be a deaminated alcohol of BSO.

The lack of $\mathrm{As}(\mathrm{III})$-thiol complexation in the BSO-treated duckweed was associated with greatly increased sensitivity to As; a 14.5 fold decrease in the $\mathrm{EC}_{20}$, based on the tissue As concentration, was observed (Fig. 3). The fact that BSO did not affect the growth and survival of $W$. globosa in the absence or at the low concentration of arsenate suggests that its effect was specifically upon the synthesis of thiol compounds. The unbound As in the + BSO-treated tissue consisted of arsenite $(\sim 70 \%)$ and arsenate ( $\sim 30 \%$ ) (Fig. 3 ); both are highly toxic to cellular metabolism (Hughes, 2002).

The BSO treatment not only sensitized W. globosa toward As, but also greatly decreased As accumulation (Fig. 2). This effect was not due to a direct suppression of arsenate uptake or an increased arsenite efflux from the cells, because there was no significant 
Table 1

The concentrations ( $\mathrm{nmol}$ As $\mathrm{g}^{-1} \mathrm{FW} \pm \mathrm{SE}$ ) of unbound As and As (III)-thiol complexes in $W$. globosa treated with $10 \mu \mathrm{M}$ arsenate with or without BSO ( $n=4$ ).

\begin{tabular}{|c|c|c|c|c|c|c|c|c|c|}
\hline \multirow[t]{2}{*}{ Treatment } & \multicolumn{2}{|l|}{ Unbound } & \multicolumn{4}{|c|}{ As(III)-thiol complexes } & \multirow[t]{2}{*}{ Total As } & \multicolumn{2}{|c|}{ Percentage (\%) } \\
\hline & Inorganic As & Unknown $(\mathrm{RT}=504 \mathrm{~s})$ & $\mathrm{As}(\mathrm{III})-\mathrm{GS}-\mathrm{PC}_{2}$ & $\mathrm{As}(\mathrm{III})-\mathrm{PC}_{3}$ & $\mathrm{As}(\mathrm{III})-\left(\left(\mathrm{PC}_{2}\right)_{2}\right.$ & $\mathrm{As}(\mathrm{III})-\mathrm{PC}_{4}$ & & Unbound & Bound \\
\hline$-\mathrm{BSO}$ & $7.76 \pm 0.76$ & $0.31 \pm 0.02$ & $0.81 \pm 0.09$ & $8.28 \pm 0.63$ & $2.85 \pm 0.56$ & $9.52 \pm 0.68$ & 29.65 & 26.2 & 73.8 \\
\hline$+\mathrm{BSO}$ & $9.66 \pm 0.66$ & 0 & 0 & 0 & 0 & 0 & 9.66 & 100 & 0 \\
\hline
\end{tabular}

effect of BSO on either process during the initial $10 \mathrm{~h}$ of arsenate exposure (Fig. 5). However, both arsenate uptake and arsenite efflux were decreased by BSO during the $10-24 \mathrm{~h}$ period. It is likely that As toxicity occurred during the later period of arsenate exposure in the +BSO treatment because of the lack of thiol synthesis and $\mathrm{As}$ (III) complexation. At $24 \mathrm{~h}$, the As concentrations in the duckweed were 38 and $50 \mathrm{mg} \mathrm{kg}^{-1}$ dry weight in the -BSO and $+\mathrm{BSO}$ treatments, respectively. These concentrations would be toxic to the duckweed in the presence of BSO but not in the - BSO control (Fig. 3). The As toxicity in the BSO-treated duckweed may in turn lead to a suppression of arsenate uptake as a result of the disturbance in cellular metabolism and, consequently, also a smaller arsenite efflux. Therefore, the ability to complex and detoxify As(III) appears to be a key factor in determining the storage capacity of As in the cells of $W$. globosa. As(III)-thiol complexes are likely to be stored in the vacuoles (Moore et al., 2011). Vacuolar transporters for As(III)-PCs have been identified in Arabidopsis recently (Song et al., 2010). The effect of BSO on As accumulation in W. globosa is similar to that observed in Arabidopsis (Liu et al., 2010). However, decreased As(III)-thiol complexation in the BSO-treated Arabidopsis was found to be associated with an increased As(III) efflux to the external medium, which was not observed in W. globosa. Also, W. globosa has no root-to-shoot transport barrier which tends to limit As translocation to the shoots in terrestrial plants. This may also explain the relatively high As accumulation in the duckweed (Zhang et al., 2009). Increased As accumulation in $H$. verticillata in response to increased $S$ supply may also be explained by increased PC synthesis and As(III)-thiol complexation (Srivastava and D'Souza, 2009).

Similar to many terrestrial plants (Zhao et al., 2009), W. globosa also has a large capacity to reduce arsenate to arsenite (Fig. 4). This reduction was suppressed by BSO, as has also been observed in Arabidopsis (Liu et al., 2010). There may be multiple pathways of arsenate reduction in plants (Zhao et al., 2009); one of them may involve an arsenate reductase like yeast ACR2 which uses GSH as the reductant (Bleeker et al., 2006; Duan et al., 2007). There may be GSH-independent pathways of arsenate reduction, because the BSO-treated duckweed, depleted of GSH, was still able to reduce a substantial proportion of arsenate to arsenite (Fig. 5). Another possibility is that uncomplexed arsenite in the BSO-treated duckweed was more prone to re-oxidation to arsenate in the cells,

Table 2

The concentrations ( $\mathrm{nmol} \mathrm{S} \mathrm{g}{ }^{-1} \mathrm{FW}$ ) of free thiol and other S-containing compounds in $W$. globosa treated with $10 \mu \mathrm{M}$ arsenate with or without BSO $(n=4)$.

\begin{tabular}{|c|c|c|c|}
\hline \multirow[t]{2}{*}{ BSO tre } & \multirow[t]{2}{*}{ Sulphur species } & \multicolumn{2}{|c|}{ Concentration (nmol S g $\left.{ }^{-1} \mathrm{FW}\right)$} \\
\hline & & Mean & SE \\
\hline \multirow[t]{5}{*}{$-\mathrm{BSO}$} & GSH & 140.7 & 22.5 \\
\hline & Reduced $\mathrm{PC}_{2}$ & 60.0 & 7.6 \\
\hline & Oxidized $\mathrm{PC}_{2}$ & 5.9 & 0.9 \\
\hline & Oxidized $\mathrm{PC}_{3}$ & 26.2 & 2.7 \\
\hline & $\begin{array}{l}\text { Mix of } \mathrm{As}(\mathrm{III})-\mathrm{PC}_{3} \& \\
\text { reduced } \mathrm{PC}_{3}\end{array}$ & 40.1 & 4.5 \\
\hline \multirow[t]{3}{*}{$+\mathrm{BSO}$} & $m / z 223.11$ (BSO) & 1373.0 & 101.8 \\
\hline & $m / z 224.09$ (deaminated BSO) & 196.9 & 14.5 \\
\hline & m/z 309.11 (unknown) & 58.1 & 5.0 \\
\hline
\end{tabular}

although the mechanism for arsenite oxidation inside plant cells remains unknown.

\section{Conclusions}

The present study has demonstrated that the essential role of PCs in As tolerance in As non-hyperaccumulating terrestrial plants is conserved in the aquatic macrophyte $W$. globosa. The synthesis of PCs also plays an important role in As accumulation and arsenate reduction in $W$. globosa. Arsenic metabolism and tolerance in nonhyperaccumulating plants are strongly linked to glutathione and PC biosynthesis.

\section{Acknowledgements}

This study was partly supported by the International Foundation for Science (NO. C/4973-1) and the Natural Science Foundation of China (41101246). X. Zhang thanks Chinese Academy of Sciences for a six-month fellowship to visit Rothamsted. M.K.U. was supported by an EPSRC research studentship (EP/E061303). Rothamsted Research is an institute of the UK Biotechnology and Biological Sciences Research Council.

\section{Appendix. Supplementary data}

Supplementary data associated with this article can be found, in the online version, at doi:10.1016/j.envpol.2012.02.009

\section{References}

Bleeker, P.M., Hakvoort, H.W.J., Bliek, M., Souer, E., Schat, H., 2006. Enhanced arsenate reduction by a CDC25-like tyrosine phosphatase explains increased phytochelatin accumulation in arsenate-tolerant Holcus lanatus. Plant Journal 45, 917-929.

Bluemlein, K., Raab, A., Meharg, A.A., Charnock, J.M., Feldmann, J., 2008. Can we trust mass spectrometry for determination of arsenic peptides in plants: comparison of LC-ICP-MS and LC-ES-MS/ICP-MS with XANES/EXAFS in analysis of Thunbergia alata. Analytical and Bioanalytical Chemistry 390, 1739-1751.

Bluemlein, K., Krupp, E.M., Feldmann, J., 2009. Advantages and limitations of a desolvation system coupled online to HPLC-ICPqMS/ES-MS for the quantitative determination of sulfur and arsenic in arseno-peptide complexes. Journal of Analytical Atomic Spectrometry 24, 108-113.

Brammer, H., Ravenscroft, P., 2009. Arsenic in groundwater: a threat to sustainable agriculture in south and south-east Asia. Environment International 35, 647-654.

Dittmar, J., Voegelin, A., Maurer, F., Roberts, L.C., Hug, S.J., Saha, G.C., Ali, M.A., Badruzzaman, A.B.M., Kretzschmar, R., 2010. Arsenic in soil and irrigation water affects arsenic uptake by rice: complementary insights from field and pot studies. Environmental Science \& Technology 44, 8842-8848.

Duan, G.L., Zhou, Y., Tong, Y.P., Mukhopadhyay, R., Rosen, B.P., Zhu, Y.G., 2007. A CDC25 homologue from rice functions as an arsenate reductase. New Phytologist $174,311-321$.

Gasic, K., Korban, S.S., 2007. Transgenic Indian mustard (Brassica juncea) plants expressing an Arabidopsis phytochelatin synthase (AtPCS1) exhibit enhanced As and Cd tolerance. Plant Molecular Biology 64, 361-369.

Griffith, O.W., Meister, A., 1979. Potent and specific-inhibition of glutathione synthesis by buthionine sulfoximine (s-normal-butyl homocysteine sulfoximine). Journal of Biological Chemistry 254, 7558-7560.

Guo, J.B., Dai, X.J., Xu, W.Z., Ma, M., 2008. Overexpressing GSH1 and AsPCS1 simultaneously increases the tolerance and accumulation of cadmium and arsenic in Arabidopsis thaliana. Chemosphere 72, 1020-1026.

Ha, S.B., Smith, A.P., Howden, R., Dietrich, W.M., Bugg, S., O’Connell, M.J., Goldsbrough, P.B., Cobbett, C.S., 1999. Phytochelatin synthase genes from Arabidopsis and the yeast Schizosaccharomyces pombe. Plant Cell 11, 1153-1163. 
Hughes, M.F., 2002. Arsenic toxicity and potential mechanisms of action. Toxicology Letters 133, 1-16.

Indriolo, E., Na, G., Ellis, D., Salt, D.E., Banks, J.A., 2010. A vacuolar arsenite transporter necessary for arsenic tolerance in the arsenic hyperaccumulating fern Pteris vittata is missing in flowering plants. Plant Cell 22, 2045-2057.

Li, Y.J., Dhankher, O.P., Carreira, L., Lee, D., Chen, A., Schroeder, J.I., Balish, R.S. Meagher, R.B., 2004. Overexpression of phytochelatin synthase in Arabidopsis leads to enhanced arsenic tolerance and cadmium hypersensitivity. Plant and Cell Physiology 45, 1787-1797.

Liu, W.J., Wood, B.A., Raab, A., McGrath, S.P., Zhao, F.J., Feldmann, J., 2010. Complexation of arsenite with phytochelatins reduces arsenite efflux and translocation from roots to shoots in Arabidopsis. Plant Physiology 152, 2211-2221.

Lombi, E., Zhao, F.J., Fuhrmann, M., Ma, L.Q., McGrath, S.P., 2002. Arsenic distribution and speciation in the fronds of the hyperaccumulator Pteris vittata. New Phytologist 156, 195-203.

Meharg, A.A., Rahman, M., 2003. Arsenic contamination of Bangladesh paddy field soils: Implications for rice contribution to arsenic consumption. Environmental Science \& Technology 37, 229-234.

Meharg, A.A., Williams, P.N., Adomako, E., Lawgali, Y.Y., Deacon, C., Villada, A. Cambell, R.C.J., Sun, G., Zhu, Y.G., Feldmann, J., Raab, A., Zhao, F.J., Islam, R., Hossain, S., Yanai, J., 2009. Geographical variation in total and inorganic arsenic content of polished (white) rice. Environmental Science \& Technology 43, 1612-1617.

Moore, K.L., Schröder, M., Wu, Z.C., Martin, B.G.H., Hawes, C.R., McGrath, S.P., Hawkesford, M.J., Ma, J.F., Zhao, F.J., Grovenor, C.R.M., 2011. NanoSIMS analysis reveals contrasting patterns of arsenic and silicon localization in rice roots. Plant Physiology 156, 913-924.

National Research Council, 2001. Arsenic in Drinking Water 2001 Update. Washington, DC.

Pickering, I.J., Gumaelius, L., Harris, H.H., Prince, R.C., Hirsch, G., Banks, J.A., Salt, D.E., George, G.N., 2006. Localizing the biochemical transformations of arsenate in a hyperaccumulating fern. Environmental Science \& Technology 40, 5010-5014

Raab, A., Feldmann, J., Meharg, A.A., 2004. The nature of arsenic-phytochelatin complexes in Holcus lanatus and Pteris cretica. Plant Physiology 134, 1113-1122.

Raab, A., Schat, H., Meharg, A.A., Feldmann, J., 2005. Uptake, translocation and transformation of arsenate and arsenite in sunflower (Helianthus annuus): formation of arsenic-phytochelatin complexes during exposure to high arsenic concentrations. New Phytologist 168, 551-558.

Raab, A., Ferreira, K., Meharg, A.A., Feldmann, J., 2007. Can arsenic-phytochelatin complex formation be used as an indicator for toxicity in Helianthus annuus? Journal of Experimental Botany 58, 1333-1338.

Rahman, M.A., Hasegawa, H., 2011. Aquatic arsenic: phytoremediation using floating macrophytes. Chemosphere 83, 633-646.

Robinson, B., Kim, N., Marchetti, M., Moni, C., Schroeter, L., van den Dijssel, C., Milne, G., Clothier, B., 2006. Arsenic hyperaccumulation by aquatic macrophytes in the Taupo Volcanic Zone, New Zealand. Environmental and Experimental Botany 58, 206-215.
Schat, H., Llugany, M., Vooijs, R., Hartley-Whitaker, J., Bleeker, P.M., 2002. The role of phytochelatins in constitutive and adaptive heavy metal tolerances in hyperaccumulator and non-hyperaccumulator metallophytes. Journal of Experimental Botany 53, 2381-2392.

Schmöger, M.E.V., Oven, M., Grill, E., 2000. Detoxification of arsenic by phytochelatins in plants. Plant Physiology 122, 793-801.

Song, W.Y., Park, J., Mendoza-Cozatl, D.G., Suter-Grotemeyer, M., Shim, D., Hortensteiner, S., Geisler, M., Weder, B., Rea, P.A., Rentsch, D., Schroeder, J.I., Lee, Y., Martinoia, E., 2010. Arsenic tolerance in Arabidopsis is mediated by two ABCC-type phytochelatin transporters. Proceedings of the National Academy of Sciences of the United States of America 107, 21187-21192.

Srivastava, S., D’Souza, S.F., 2009. Increasing sulfur supply enhances tolerance to arsenic and its accumulation in Hydrilla verticillata (L.f.) Royle. Environmental Science \& Technology 43, 6308-6313.

Srivastava, S., Mishra, S., Tripathi, R.D., Dwivedi, S., Trivedi, P.K., Tandon, P.K., 2007. Phytochelatins and antioxidant systems respond differentially during arsenite and arsenate stress in Hydrilla verticillata (L.f) Royle. Environmental Science \& Technology 41, 2930-2936.

Ullrich-Eberius, C.I., Sanz, A., Novacky, A.J., 1989. Evaluation of arsenate- and vanadate-associated changes of electrical membrane potential and phosphate transport in Lemna gibba-G1. Journal of Experimental Botany 40, 119-128.

Webb, S.M., Gaillard, J.F., Ma, L.Q., Tu, C., 2003. XAS speciation of arsenic in a hyperaccumulating fern. Environmental Science \& Technology 37, 754-760.

Xu, X.Y., McGrath, S.P., Zhao, F.J., 2007. Rapid reduction of arsenate in the medium mediated by plant roots. New Phytologist 176, 590-599.

Zhang, W.H., Cai, Y., Downum, K.R., Ma, L.Q., 2004. Thiol synthesis and arsenic hyperaccumulation in Pteris vittata (Chinese brake fern). Environmental Pollution 131, 337-345.

Zhang, X., Lin, A.J., Zhao, F.J., Xu, G.Z., Duan, G.L., Zhu, Y.G., 2008. Arsenic accumulation by the aquatic fern Azolla: comparison of arsenate uptake, speciation and efflux by $A$. caroliniana and $A$. filiculoides. Environmental Pollution 156, 1149-1155.

Zhang, X., Zhao, F.J., Huang, Q., Williams, P.N., Sun, G.X., Zhu, Y.G., 2009. Arsenic uptake and speciation in the rootless duckweed Wolffia globosa. New Phytologist $182,421-428$.

Zhao, F.J., Wang, J.R., Barker, J.H.A., Schat, H., Bleeker, P.M., McGrath, S.P., 2003. The role of phytochelatins in arsenic tolerance in the hyperaccumulator Pteris vittata. New Phytologist 159, 403-410.

Zhao, F.J., Ma, J.F., Meharg, A.A., McGrath, S.P., 2009. Arsenic uptake and metabolism in plants. New Phytologist 181, 777-794.

Zhao, F.J., Ago, Y., Mitani, N., Li, R.Y., Su, Y.H., Yamaji, N., McGrath, S.P., Ma, J.F., 2010a. The role of the rice aquaporin Lsi1 in arsenite efflux from roots. New Phytologist 186, 392-399.

Zhao, F.J., McGrath, S.P., Meharg, A.A., 2010b. Arsenic as a food-chain contaminant: mechanisms of plant uptake and metabolism and mitigation strategies. Annual Review of Plant Biology 61, 535-559.

Zhu, Y.G., Williams, P.N., Meharg, A.A., 2008. Exposure to inorganic arsenic from rice: a global health issue? Environmental Pollution 154, 169-171. 